\title{
Vibration control of a flexible structure with electromagnetic actuators
}

\section{Gruzman, Maurício; Santos, IImar}

Published in:

Journal of the Brazilian Society of Mechanical Sciences and Engineering

Link to article, DOI:

10.1007/s40430-015-0438-x

Publication date:

2016

Document Version

Peer reviewed version

Link back to DTU Orbit

\section{Citation (APA):}

Gruzman, M., \& Santos, I. (2016). Vibration control of a flexible structure with electromagnetic actuators. Journal of the Brazilian Society of Mechanical Sciences and Engineering, 38(4), 1131-1142.

https://doi.org/10.1007/s40430-015-0438-x

\section{General rights}

Copyright and moral rights for the publications made accessible in the public portal are retained by the authors and/or other copyright owners and it is a condition of accessing publications that users recognise and abide by the legal requirements associated with these rights.

- Users may download and print one copy of any publication from the public portal for the purpose of private study or research.

- You may not further distribute the material or use it for any profit-making activity or commercial gain

- You may freely distribute the URL identifying the publication in the public portal 


\title{
Vibration control of a flexible structure with electromagnetic actuators
}

\author{
Maurício Gruzman \\ Department of Mechanical and Materials Engineering \\ Military Institute of Engineering, IME \\ Praça General Tibúrcio 80, Urca, Rio de Janeiro-RJ \\ CEP 22290-270 \\ Brazil \\ e-mail: gruzman@ime.eb.br \\ Tel.: 5521 2546-7084 \\ Ilmar Ferreira Santos \\ Department of Mechanical Engineering \\ Technical University of Denmark, DTU \\ Kongens Lyngby, 2800 \\ Denmark
}

\begin{abstract}
This work presents the model of a shear frame type structure composed of six flexible beams and three rigid masses. Fixed on the ground, outside the structure, two voltage controlled electromagnetic actuators are used for vibration control. To model the flexible beams, unidimensional finite elements were used. Non-linear equations for the actuators electromagnetic force, noise in the position sensor, time delays for the control signal update and voltage saturation were also considered in the model. For controlling purposes a discrete linear quadratic regulator combined with a predictive full-order discrete linear observer was employed. Results of numerical simulations, where the structure is submitted to an impulsive disturbance force and to a harmonic force, show that the oscillations can be significantly reduced with the use of the electromagnetic actuators.
\end{abstract}

Keywords Structures. Vibration Control. Electromagnetic actuators. Discrete linear quadratic regulator.

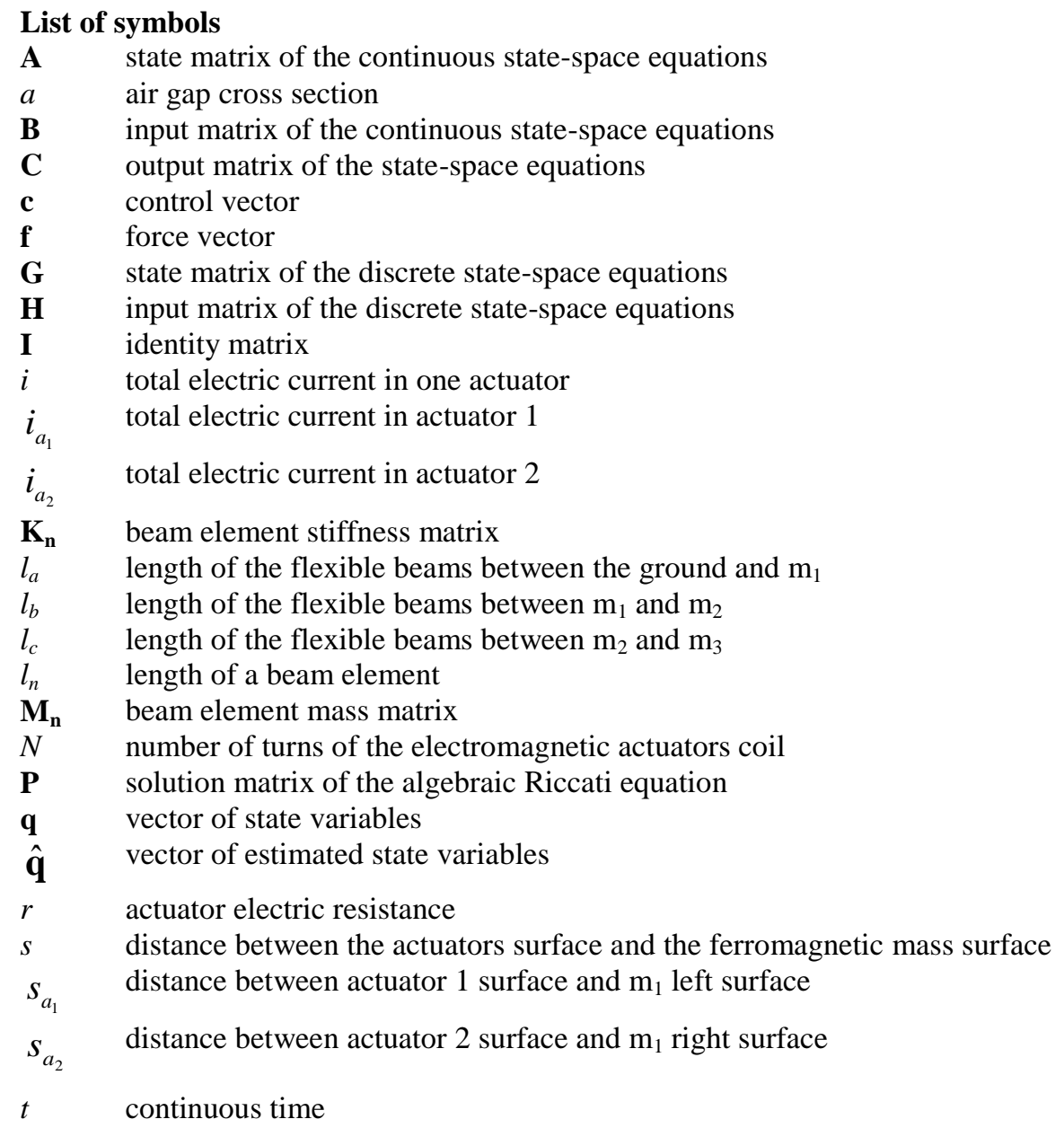




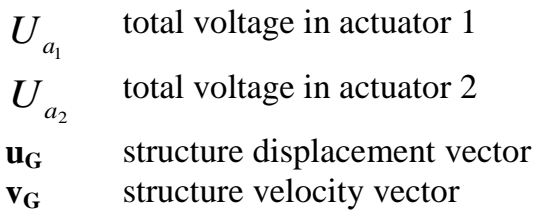

\section{Introduction}

When dynamic forces are applied in structures, undesired oscillations may occur. There are many ways to minimize those oscillations. Passive, semi-active and active methods are extensively described in literature. A common passive method consist of using dynamic vibration absorbers, also known as tuned mass dampers, constructed with a mass and a spring (or a mass, a spring and a viscous damper), as described in [10, 15, 16, 24, 27, 34]. Despite its effectiveness when periodic forces are applied, they are limited to some frequency range. In order to allow an effective operation in a wider force frequency range, [14] proposes the use of multiple degrees of freedom vibration absorbers. Other type of passive solutions can be achieved with the use of resonant circuit shunted piezoeletrics [23, 25, 27, 31], use of viscoelastic materials [10] or shape memory alloys [9]. Alternative techniques, as the use of passive electromagnetic dampers, can be found in [22].

Semi-active methods often bring better vibration reduction but without the power consumption required by the active methods. The magnetorheological dampers, described in details by [19, 23], are commonly mentioned in literature. Examples of those dampers with different controllers can be found in $[3,12,33]$, where special attention is given for control of structural vibration caused by earthquakes. Another type of a semi-active technique can be found in [30], where a coil based electromagnetic vibration control device has been used.

The most effective class of vibration control devices are of the active type. They can be used to reduce the oscillations due to periodic disturbances in wider frequency ranges as well as oscillations caused by impulsive disturbances. Different active methods for vibration control can be used. A widely used method consists in employing piezoelectric actuators, as shown in $[1,2,7,8]$, where they are used in combination with different controllers. In [25] an active-passive piezoelectric network is presented. Another active technique consist in using reaction masses, as presented in [5, 13]. In [13] a comparison between the performance of an active controller that uses reaction masses and a passive controller is presented. Recently, electromagnetic actuators, assembled and fixed outside the structure, have been used to control vibration of flexible beams. In [11, 18, 32] a single actuator is employed. In [17] two actuators are used, allowing electromagnetic forces in opposite directions. In [29] two actuators are used to control the vibration of a moving mass attached to a rigid arm that can rotate with respect to the ground.

The use of electromagnetic actuators is very efficient and they are assembled outside and without any physical contact with the structure whose oscillations need to be controlled. This makes their use an interesting solution when actuators cannot be assembled directly at the structure. Besides, when oscillations that were not expected during the design stage need to be reduced, the use of those external actuators may be cheaper than modifying a structure that has already been constructed. Despite the mentioned vantages of the electromagnetic actuators they have a main drawback, the relative motion between the actuator surface and the actuated part of the structure need to be very small [26, 28], usually less than one millimeter. But if this motion can be kept small, the use of electromagnetic actuators assembled outside the structure is viable.

In this work electromagnetic actuators will be employed to control the vibrations of a structure due to an impulsive force. For that, a model of the structure, actuator and the controller will be developed and simulation results will be presented to show the effectiveness of this vibration control technique.

\section{Structure, actuators and position sensor}

According to the scheme bellow, the shear frame type structure considered at this work is composed of three rigid masses $\left(m_{1}, m_{2}\right.$ and $\left.m_{3}\right)$, connected to each other with flexible elements $\left(b_{3}, b_{4}, b_{5}\right.$ and $\left.b_{6}\right)$. The first rigid mass is also connected to the ground with flexible elements $\left(b_{1}\right.$ and $\left.b_{2}\right)$. To control the vibrations, two electromagnetic actuators $\left(a_{1}\right.$ and $\left.a_{2}\right)$ are fixed to the ground in such a way to exert forces in $\mathrm{m}_{1}$. In order to have magnetic forces acting at the structure, $\mathrm{m}_{1}$ should consist of a ferromagnetic material or should have ferromagnetic material at its surfaces facing the actuators. To measure $\mathrm{m}_{1}$ displacement a position sensor (p) is assembled near one of its lateral surfaces. For controlling purposes, it will be considered that a digital computer is used.

Considering that the thickness of the flexible structures are much smaller than its width and considering that $b_{1}$ is identical and parallel to $b_{2}$, that $b_{3}$ is identical and parallel to $b_{4}$, and, that $b_{5}$ is 
identical and parallel to $b_{6}$, it can be assumed that the masses will only move parallel to the ground fixed $\mathrm{X}$ axis. Therefore all the analysis will be made considering forces applied in this direction, according to the figure below, where a disturbance force, $f(t)$, applied at $\mathrm{m}_{3}$ is shown.

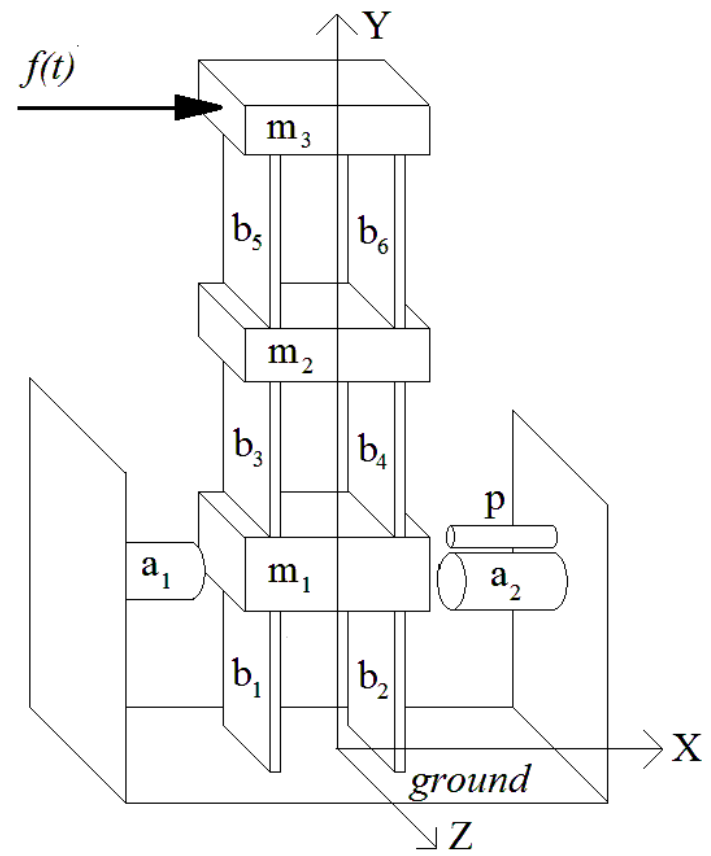

Fig. 1 Shear frame structure

\subsection{Structure model}

If the length of each flexible element is significantly larger than its width and thickness, unidimensional finite elements can be used for modeling purposes. Considering that the rigid masses will move only in directions parallel to $\mathrm{X}$ axis, beam elements with two knots and four degrees of freedom can be employed for the discretization of the flexible elements in the structure $\left(b_{1}, b_{2}, b_{3}, b_{4}, b_{5}\right.$ and $\left.b_{6}\right)$. The degrees of freedom of a beam element $n$ are represented bellow.

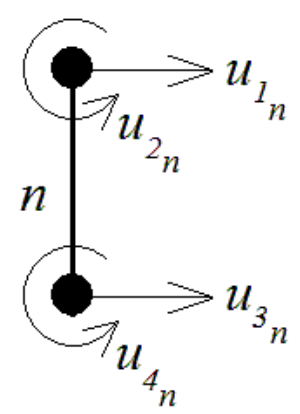

Fig. 2 Beam element with two knots and four degrees of freedom

The stiffness matrix and the consistent mass matrix of a flexible beam element with constant specific mass $\rho$, constant cross section area $A$, constant area moment of inertia $I$, constant elasticity modulus $E$ and with length $l_{n}$ are respectively given by [15]:

$$
\mathbf{K}_{n}=E I\left[\begin{array}{cccc}
12 / l_{n}^{3} & 6 / l_{n}^{2} & -12 / l_{n}^{3} & 6 / l_{n}^{2} \\
6 / l_{n}^{2} & 4 / l_{n} & -6 / l_{n}^{2} & 2 / l_{n} \\
-12 / l_{n}^{3} & -6 / l_{n}^{2} & 12 / l_{n}^{3} & -6 / l_{n}^{2} \\
6 / l_{n}^{2} & 2 / l_{n} & -6 / l_{n}^{2} & 4 / l_{n}
\end{array}\right]
$$


$\mathbf{M}_{n}=\frac{\rho A}{420}\left[\begin{array}{cccc}156 l_{n} & 22 l_{n}^{2} & 54 l_{n} & -13 l_{n}^{2} \\ 22 l_{n}^{2} & 4 l_{n}^{3} & 13 l_{n}^{2} & -3 l_{n}^{3} \\ 54 l_{n} & 13 l_{n}^{2} & 156 l_{n} & -22 l_{n}^{2} \\ -13 l_{n}^{2} & -3 l_{n}^{3} & -22 l_{n}^{2} & 4 l_{n}^{3}\end{array}\right]$

For a flexible beam with constant cross section area of width $w$ and thickness $h$ :

$A=h w$

$I=h w^{3} / 12$

If two beam elements with the same length are used for the discretization of each flexible beam in the structure, a model with 12 beam elements and 15 degrees of freedom is obtained. The subscript $G$ is used to indicate that the degrees of freedom are referred to the whole structure (global degrees of freedom). The structure also contains three rigid elements $\mathrm{m}_{1}, \mathrm{~m}_{2}$ and $\mathrm{m}_{3}$.

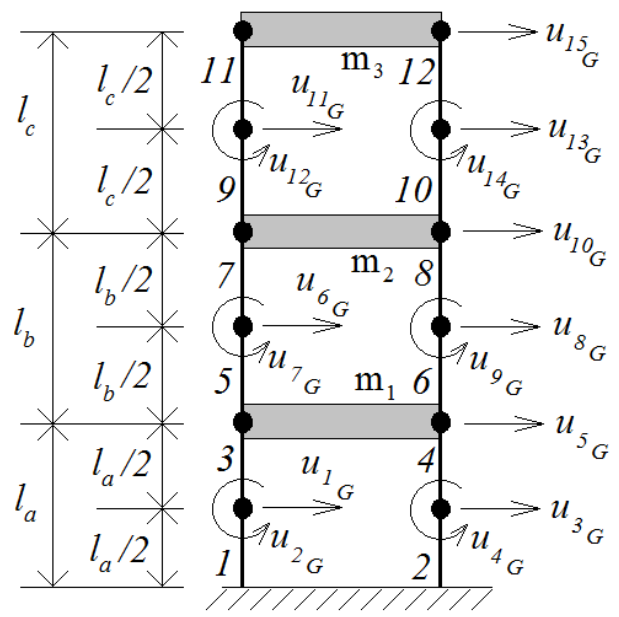

Fig. 3 Discretized structure

The global stiffness matrix, $\mathbf{K}_{G}$, and the consistent mass matrix, $\mathbf{M}_{G}$, represented with Eqs. (5) and (6), can be obtained from the mass and stiffness matrices of each beam element according to the methods discussed in [15]:

$$
\begin{aligned}
\mathbf{K}_{G} & =\left[\begin{array}{ccc}
k_{1,1} & \cdots & k_{1,15} \\
\vdots & \ddots & \vdots \\
k_{15,1} & \cdots & k_{15,15}
\end{array}\right] \\
\mathbf{M}_{G} & =\left[\begin{array}{ccc}
m_{1,1} & \cdots & m_{1,15} \\
\vdots & \ddots & \vdots \\
m_{15,1} & \cdots & m_{15,15}
\end{array}\right]
\end{aligned}
$$

The elements of the matrices above are given in the Appendix. Since $u_{5_{G}}, u_{10_{G}}$ and $u_{15_{G}}$ describe, respectively, the displacements of $\mathrm{m}_{1}, \mathrm{~m}_{2}$ and $\mathrm{m}_{3}$, those masses were added at the components $m_{5,5}$, $m_{10,10}$ and $m_{15,15}$ of the global consistent mass matrix.

Considering that the structure has proportional damping, then, according to [15, 24], the viscous damping matrix, $\mathbf{D}_{G}$, can be calculated with Eq. (7). 
$\mathbf{D}_{G}=\alpha \mathbf{M}_{G}+\beta \mathbf{K}_{G}$

If the first two modal damping factors, $\zeta_{1}$ and $\zeta_{2}$, and the first two natural angular frequencies of the structure $\left(\omega_{1}\right.$ and $\left.\omega_{2}\right)$ are known, the coefficients $\alpha$ and $\beta$ can be calculated using with the following system of equations [15]:

$$
\left\{\begin{array}{l}
\zeta_{1}=\frac{\alpha}{2 \omega_{1}}+\frac{\beta \omega_{1}}{2} \\
\zeta_{2}=\frac{\alpha}{2 \omega_{2}}+\frac{\beta \omega_{2}}{2}
\end{array}\right.
$$

Which can solved for $\alpha$ and $\beta$ :

$$
\left\{\begin{array}{l}
\alpha=2\left(\zeta_{2}-\frac{\zeta_{1} \omega_{2}}{\omega_{1}}\right) /\left(\frac{1}{\omega_{2}}-\frac{\omega_{2}}{\omega_{1}^{2}}\right) \\
\beta=2 \zeta_{1} / \omega_{1}-2\left(\zeta_{2}-\frac{\zeta_{1} \omega_{2}}{\omega_{1}}\right) /\left(\frac{\omega_{1}^{2}}{\omega_{2}}-\omega_{2}\right)
\end{array}\right.
$$

\subsection{Actuators models}

An electromagnetic actuator can only exert an attractive force at a ferromagnetic material. According to $[26,28]$, the magnitude of this force can be modeled as:

$$
f_{a}(t)=\frac{1}{4} \mu_{0} N^{2} a \frac{i(t)^{2}}{s(t)^{2}}
$$

Where, $\mu_{0}$ is the magnetic field constant of the vacuum

Considering that the two actuators, $\mathrm{a}_{1}$ and $\mathrm{a}_{2}$, are identical, with $\mathrm{a}_{1}$ pulling $\mathrm{m}_{1}$ to the left and $\mathrm{a}_{2}$ pulling it to the right, the forces exerted by the actuator $\mathrm{a}_{1}$ and $\mathrm{a}_{2}$ are respectively given by:

$$
\begin{aligned}
& f_{a_{1}}(t)=-\frac{1}{4} \mu_{0} N^{2} a \frac{i_{a_{1}}(t)^{2}}{s_{a_{1}}(t)^{2}}=-\frac{1}{4} \mu_{0} N^{2} a \frac{i_{a_{1}}(t)^{2}}{\left[s_{0}+u_{5_{G}}(t)\right]^{2}} \\
& f_{a_{2}}(t)=\frac{1}{4} \mu_{0} N^{2} a \frac{i_{a_{2}}(t)^{2}}{s_{a_{2}}(t)^{2}}=\frac{1}{4} \mu_{0} N^{2} a \frac{i_{a_{2}}(t)^{2}}{\left[s_{0}-u_{5_{G}}(t)\right]^{2}}
\end{aligned}
$$

Where, $s_{0}$ is the air gap between each actuators surface and the ferromagnetic surfaces of the rigid mass $m_{1}$ when the structure is in equilibrium position, as shown in Fig. 4. 


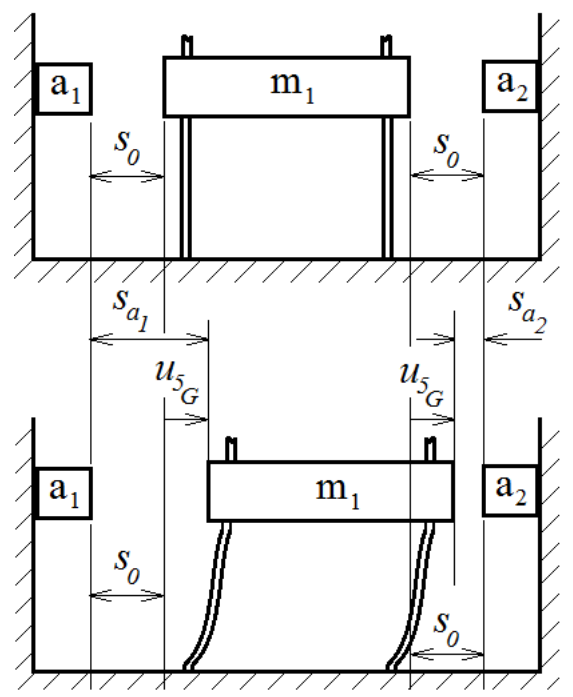

Fig. 4 Displacement of $m_{1}$ with respect to equilibrium position

If voltage control is used, the currents at each actuator can be calculated with the following differential equations bellow [26]:

$$
\begin{aligned}
& r i_{a_{1}}(t)+L \dot{i}_{a_{1}}(t)-k_{u} \dot{u}_{5_{G}}(t)=U_{a_{1}}(t) \\
& r i_{a_{2}}(t)+L \dot{i}_{a_{2}}(t)+k_{u} \dot{u}_{5_{G}}(t)=U_{a_{2}}(t)
\end{aligned}
$$

To have a more realistic model, variable inductance $(L)$ and variable voltage-velocity coefficient $\left(k_{u}\right)$ will be considered. The inductance depends on the gap between the actuator surface and the ferromagnetic material surface. The voltage-velocity coefficient depends on this gap and the actuators current. Therefore, equations 13 and 14 can be re-written as:

$$
\begin{aligned}
& r i_{a_{1}}(t)+L\left(s_{a_{1}}\right) \dot{i}_{a_{1}}(t)-k_{u}\left(s_{a_{1}}, i_{a_{1}}\right) \dot{u}_{5_{G}}(t)=U_{a_{1}}(t) \\
& r i_{a_{2}}(t)+L\left(s_{a_{2}}\right) \cdot \dot{i}_{a_{2}}(t)+k_{u}\left(s_{a_{2}}, i_{a_{2}}\right) \dot{u}_{5_{G}}(t)=U_{a_{2}}(t)
\end{aligned}
$$

An empirical formula for the inductance in function of the air gap $s$ is given in [4]:

$$
L(s)=L_{0}+\left(L_{\max }-L_{0}\right) /(1+\gamma \cdot s)
$$

Where, $L_{o}$ is the inductance when the ferromagnetic element is not present, $L_{\max }$ is the inductance when the ferromagnetic material is touching the actuator and $\gamma$ is a parameter. If the inductance when the ferromagnetic material is at some distance $d$ from the actuator's surface is known (i.e. $L_{d}$ ) the parameter $\gamma$ can be calculated:

$$
\begin{aligned}
& L_{d}=L(d)=L_{0}+\left(L_{\max }-L_{0}\right) /(1+\gamma \cdot d) \\
& \gamma=\frac{1}{d} \cdot\left(\frac{L_{\text {max }}-L_{0}}{L_{d}-L_{0}}-1\right)
\end{aligned}
$$

Therefore, Eq. (17), applied to actuator $\mathrm{a}_{1}$ and actuator $\mathrm{a}_{2}$, becomes: 


$$
\begin{aligned}
& L\left(s_{a_{1}}\right)=L_{0}+\frac{\left(L_{\max }-L_{0}\right)}{1+\frac{s_{a_{1}}}{d} \cdot\left(\frac{L_{\max }-L_{0}}{L_{d}-L_{0}}-1\right)}=L_{0}+\frac{\left(L_{\max }-L_{0}\right)}{1+\frac{\left[s_{0}+u_{5_{G}}(t)\right]}{d} \cdot\left(\frac{L_{\max }-L_{0}}{L_{d}-L_{0}}-1\right)} \\
& L\left(s_{a_{2}}\right)=L_{0}+\frac{\left(L_{\max }-L_{0}\right)}{1+\frac{s_{a_{2}}}{d} \cdot\left(\frac{L_{\max }-L_{0}}{L_{d}-L_{0}}-1\right)}=L_{0}+\frac{\left(L_{\max }-L_{0}\right)}{1+\frac{\left[s_{0}-u_{5_{G}}(t)\right]}{d} \cdot\left(\frac{L_{\max }-L_{0}}{L_{d}-L_{0}}-1\right)}
\end{aligned}
$$

In [26] it is mentioned that when the electromagnetic force is linearized around an equilibrium gap, $s_{0}$, and a bias current, $i_{0}$, the voltage-velocity coefficient, $k_{u}$, is equal to the force-current factor, $k_{i}$, given by Eq. 22.

$k_{u}=k_{i}=\mu_{0} N^{2} a \frac{i_{0}}{s_{0}^{2}}$

For different gaps, $s$, and currents, $i$, the coefficient $k_{u}$ can be approximated by:

$$
k_{u}(i, s)=\mu_{0} N^{2} a \frac{i}{s^{2}}
$$

Therefore, for the actuator $\mathrm{a}_{1}$ current equation the coefficient $k_{u}$ will be approximated by Eq. (24) and for the actuator $\mathrm{a}_{2}$ it will be approximated by Eq. (25).

$$
\begin{aligned}
& k_{u}\left(i_{a_{1}}, s_{a_{1}}\right)=\mu_{0} N^{2} a \frac{i_{a_{1}}}{s_{a_{1}}^{2}}=\mu_{0} N^{2} a \frac{i_{a_{1}}}{\left[s_{0}+u_{5_{G}}(t)\right]^{2}} \\
& k_{u}\left(i_{a_{2}}, s_{a_{2}}\right)=\mu_{0} N^{2} a \frac{i_{a_{2}}}{s_{a_{2}}^{2}}=\mu_{0} N^{2} a \frac{i_{a_{2}}}{\left[s_{0}-u_{5_{G}}(t)\right]^{2}}
\end{aligned}
$$

The total voltage provided for each actuator will be composed of the bias voltage, $U_{0}$, and the control voltage, $U$, according to the equations bellow:

$$
\begin{aligned}
& U_{a_{1}}(t)=U_{0}-U(t) \\
& U_{a_{2}}(t)=U_{0}+U(t)
\end{aligned}
$$

The use of a bias voltage is necessary to induce a bias current at the actuators, $i_{0}$, which is necessary to allow the linearization of the resultant actuators force, as discussed in [26, 28]. With a linearized expression for the actuation force it is possible to design a linear controller. The control voltage will be obtained by the controller, discussed in details further.

Substituting Eqs. (20), (24) and (26) in Eq. (15) and substituting Eqs. (21), (25) and (27) in Eq. (16), a more accurate representation of the differential equations for the current at the actuators are obtained:

$$
r i_{a_{1}}(t)+\left[L_{0}+\frac{\left(L_{\max }-L_{0}\right)}{1+\frac{\left[s_{0}+u_{5_{G}}(t)\right]}{d}\left(\frac{L_{\max }-L_{0}}{L_{d}-L_{0}}-1\right)}\right] \dot{i}_{a_{1}}(t)-\frac{i_{a_{1}}(t) \mu_{0} N^{2} a \dot{u}_{5_{G}}(t)}{\left[s_{0}+u_{5_{G}}(t)\right]^{2}}=U_{0}-U(t)
$$




$$
r i_{a_{2}}(t)+\left[L_{0}+\frac{\left(L_{\max }-L_{0}\right)}{1+\frac{\left[s_{0}-u_{5_{G}}(t)\right]}{d}\left(\frac{L_{\max }-L_{0}}{L_{d}-L_{0}}-1\right)}\right] \dot{i_{a_{2}}}(t)+\frac{i_{a_{2}}(t) \mu_{0} N^{2} a \dot{u}_{5_{G}}(t)}{\left[s_{0}-u_{5_{G}}(t)\right]^{2}}=U_{0}+U(t)
$$

Power amplifiers used in real systems provide voltages until a superior limit, $U_{\text {sup }}$. This non-linear feature is represented at Fig. 5 and will be considered in the simulation program.

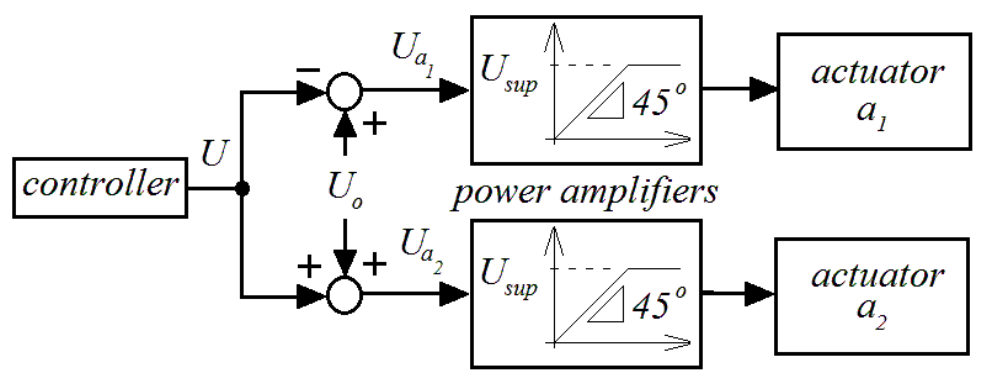

Fig. 5 Voltage saturation

In the model used in this work, hysteresis and magnetic saturation at the actuators will be disregarded. In a real system these phenomena can only be avoided if the flux density, $B$, at the actuators are kept below a limiting value, $B_{\text {lim }}$, of the metal used in its core. Eq. (30) relates the flux density with the actuators current, $i$, and the air gap $s[26]$ :

$$
B=\mu_{0} N \frac{i}{2 s}
$$

If $B$ is smaller than $B_{\text {lim }}$, the actuator will be working within the hysteresis and saturation limits. Therefore, during the simulation it is important to verify this condition to guarantee the suitability of the model used. This can be done if the condition bellow is checked at every simulation time step:

$$
\mu_{0} N \frac{i(t)}{2 s(t)}<B_{\lim } \rightarrow \frac{i(t)}{s(t)}<\frac{2 B_{\lim }}{\mu_{0} N}
$$

As there are two actuators, the conditions should be checked for each of them:

$$
\begin{gathered}
\frac{i_{a_{1}}(t)}{s_{a_{1}}(t)}=\frac{i_{a_{1}}(t)}{s_{0}+u_{5_{G}}(t)}<\frac{2 B_{\lim }}{\mu_{0} N} \\
\frac{i_{a_{2}}(t)}{s_{a_{2}}(t)}=\frac{i_{a_{2}}(t)}{s_{0}-u_{5_{G}}(t)}<\frac{2 B_{\lim }}{\mu_{0} N}
\end{gathered}
$$

\subsection{Sensor model}

There is only one sensor in the system that measures $\mathrm{m}_{1}$ position. To assure that a realistic sensor model is used noise will be included in the simulation program. The output of the sensor, $y(t)$, with noise, $\eta(t)$, is given by:

$$
y(t)=u_{5_{G}}(t)+\eta(t)
$$

The noise will be modeled as random function that can assume any value between a lower limit, $\eta_{\text {inf }}$, and an upper limit, $\eta_{\text {sup }}$. 


\section{Controller}

A system where the control is done with a digital computer is modeled in this work. The use of digital computers for controlling purposes allows the application of more sophisticated control techniques, but introduces time delays in the system. Therefore, in the model used at the simulations it is necessary to consider those time delays. Time delays due to digital controllers mean that the control signal applied at some instant $t_{k}$ is calculated with the information provided by the sensor at a previous time $t_{k-1}$. Assuming constant time delays, $T$, the relationship between two consecutive sampled times is given by:

$t_{k}=t_{k-1}+T$

Alternatively, the expression above can be written as:

$t_{k+1}=t_{k}+T$

Besides, zero order hold [20] will be considered, which means that the control signal will remain constant at the calculated value until a new value is provided by the digital computer, after $T$ seconds.

The purpose of the controller is to bring the structure back to equilibrium position (i.e., $\boldsymbol{u}_{\boldsymbol{G}}=\mathbf{0}$ ) after some disturbance force is applied. A linear quadratic regulator (LQR), described in [20,21], will be used for that. As this is a state-space regulator, it is necessary to provide the system states for the calculations of the control signal. Assuming that only one sensor is available, an observer will be used to estimate the states. In this work a full order observer will be employed, $[20,21]$. Besides, the LQR is a linear regulator, which means that it is designed based at a linear model of the system. Therefore it is necessary to develop a linear model of the system.

Due to the time delays, it is recommended to use a discrete LQR with a predictive observer. For that, a linear discrete model of the system is necessary. To avoid the estimation of too many states, the controller and the observer will be designed based in a simplified three degrees of freedom flexible structure, discussed next. Therefore, a continuous linear model of the system will be first developed. From this model, a discrete linear model of the system will be obtained, which allows the design of a discrete LQR and predictive discrete linear observer.

\subsection{Continuous simplified model}

For the controller and observer design a simplified three degrees of freedom model of the structure will be used. Within the simplified model, ideal springs linking the bodies are considered instead of the flexible beams, according to the scheme shown in the figure bellow.

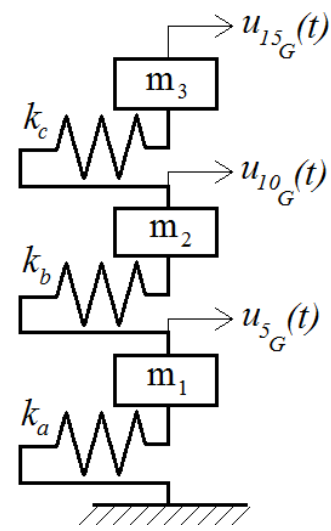

Fig. 6 Simplified model

The stiffness constant for a spring that represents two parallel flexible beams of length $l_{m}$ connecting elements that move parallel to the ground is given by [24]:

$k=24 E I / l_{m}^{3}$ 
Therefore, each of the equivalent springs will have the following stiffness:

$k_{a}=24 E I / l_{a}^{3}$

$k_{b}=24 E I / l_{b}^{3}$

$k_{c}=24 E I / l_{c}^{3}$

Each actuator exerts an attractive nonlinear force at $\mathrm{m}_{1}$. But if small displacements of $\mathrm{m}_{1}$ occur around the equilibrium position (where the air gap is equal to $s_{0}$ for both actuators, as it is shown in Fig. 4) and if the actuators currents oscillate around a bias current, $i_{0}$, an actuation resultant linear force, $f_{r}(t)$, can be approximated by, [24] and [15]:

$f_{r}(t)=k_{i} i_{x}(t)+k_{s} u_{5_{G}}(t)$

Where, $i_{x}$ is the differential current. The force-current factor, $k_{i}$, is given by Eq. (22) and the forcedisplacement factor, $k_{s}$, is given by Eq. (42), as shown in [26, 28]:

$k_{s}=\mu_{0} N^{2} a \frac{i_{0}^{2}}{s_{0}^{3}}$

It is important to stress that, as the actuators are controlled by voltage, the bias current, $i_{0}$, has to be induced by providing a bias voltage, $U_{0}$.

$i_{0}=U_{0} / r$

Therefore, the constants $k_{i}$ and $k_{s}$ can be written as:

$$
\begin{aligned}
& k_{i}=\mu_{0} N^{2} a \frac{\left(U_{0} / r\right)}{s_{0}^{2}} \\
& k_{s}=\mu_{0} N^{2} a \frac{\left(U_{0} / r\right)^{2}}{s_{0}^{3}}
\end{aligned}
$$

According to $[26,28]$, the differential current, $i_{x}$, can be calculated with Eq. (46):

$$
r i_{x}(t)+L_{a v g} \dot{i}_{x}(t)-k_{u} \dot{u}_{5_{G}}(t)=U(t)
$$

Where, $L_{a v g}$ is an average inductance value, $k_{u}$ is equal to $k_{i}$, now given by Eq. (44), and $U$ is the control voltage. Since the mass $\mathrm{m}_{1}$ will oscillate around $s_{0}$, the average value for the inductance can be obtained by considering $s=s_{0}$ in Eq. (17).

If the proportional damping coefficients $\alpha$ and $\beta$ of the structure are known, proportional damping can be included in this simplified model. The set of equations bellow, together with Eq. (46), can be used to represent the simplified structure with proportional damping.

$$
\begin{aligned}
& m_{1} \ddot{u}_{5_{G}}(t)+\left[\alpha m_{1}+\beta\left(k_{a}+k_{b}\right)\right] \dot{u}_{5_{G}}(t)-\beta k_{b} \dot{u}_{10_{G}}(t)+\left(k_{a}+k_{b}\right) u_{5_{G}}(t)-k_{b} u_{10_{G}}(t) \\
& =f_{r}(t)=k_{i} i_{x}(t)+k_{s} u_{5_{G}}(t) \\
& m_{2} \ddot{u}_{10_{G}}(t)-\beta k_{b} \dot{u}_{5_{G}}(t)+\left[\alpha m_{2}+\beta\left(k_{b}+k_{c}\right)\right] \dot{u}_{10_{G}}(t)-\beta k_{c} \dot{u}_{15_{G}}(t)-k_{b} u_{5_{G}}(t) \\
& +\left(k_{b}+k_{c}\right) u_{10_{G}}(t)-k_{c} u_{15_{G}}(t)=0
\end{aligned}
$$


$m_{3} \ddot{u}_{15_{G}}(t)-\beta k_{c} \dot{u}_{10_{G}}(t)+\left[\alpha m_{3}+\beta k_{c}\right] \dot{u}_{15_{G}}(t)-k_{c} u_{10_{G}}(t)+k_{c} u_{15_{G}}(t)=0$

Making the following variable substitution:

$q_{1}=u_{5_{G}}, q_{2}=u_{10_{G}}, q_{3}=u_{15_{G}}, q_{4}=\dot{u}_{5_{G}}, q_{5}=\dot{u}_{10_{G}}, q_{6}=\dot{u}_{15_{G}}$ and $q_{7}=i_{x}$.

The system can, finally, be written in the continuous state-space form, [34]:

$\dot{\mathbf{q}}(t)=\mathbf{A q}(t)+\mathbf{B} \mathbf{c}(t)$

Where:

$$
\begin{aligned}
& \dot{\mathbf{q}}(t)=\left[\begin{array}{lllllll}
\dot{q}_{1}(t) & \dot{q}_{2}(t) & \dot{q}_{3}(t) & \dot{q}_{4}(t) & \dot{q}_{5}(t) & \dot{q}_{6}(t) & \dot{q}_{7}(t)
\end{array}\right]^{\mathrm{T}} \\
& \mathbf{q}(t)=\left[\begin{array}{lllllll}
q_{1}(t) & q_{2}(t) & q_{3}(t) & q_{4}(t) & q_{5}(t) & q_{6}(t) & q_{7}(t)
\end{array}\right]^{\mathrm{T}} \\
& \mathbf{B}=\left[\begin{array}{llllllll}
0 & 0 & 0 & 0 & 0 & 0 & 1 / L_{\text {avg }}
\end{array}\right]^{\mathrm{T}} \\
& \mathbf{c}(t)=U(t)
\end{aligned}
$$

$$
\mathbf{A}=\left[\begin{array}{cccc}
A_{1,1} & A_{1,2} & \cdots & A_{1,7} \\
A_{2,1} & A_{2,2} & \cdots & A_{2,7} \\
\vdots & \vdots & \ddots & \vdots \\
A_{7,1} & A_{7,2} & \cdots & A_{7,7}
\end{array}\right]
$$

The elements of the matrix $\mathbf{A}$ are shown in the Appendix.

\subsection{Discrete simplified model}

The discrete state-space equations of a linear time invariant system are given by Eq. (56). It is considered that any two consecutives discrete time instants are separated by $T$ seconds.

$$
\mathbf{q}\left(t_{k+1}\right)=\mathbf{G q}\left(t_{k}\right)+\mathbf{H c}\left(t_{k}\right)
$$

Where,

$$
\mathbf{c}\left(t_{k}\right)=U\left(t_{k}\right)
$$

The discrete model can be obtained from the continuous model. After substituting the numerical value of the parameters in matrices $\mathbf{A}$ and $\mathbf{B}$, the numerical value of matrices $\mathbf{G}$ and $\mathbf{H}$ can be calculated according to the equations bellow [20]:

$$
\begin{aligned}
& \mathbf{G}=e^{\mathbf{A} T} \\
& \mathbf{H}=\left(\int_{0}^{T} e^{\mathbf{A} \lambda} d \lambda\right) \mathbf{B}
\end{aligned}
$$

\subsection{Discrete LQR design}

The LQR is a state space regulator whose control signal is given by:

$$
\mathbf{c}\left(t_{k}\right)=-\mathbf{K}_{\mathbf{C}} \mathbf{q}\left(t_{k}\right)
$$


Where, $\mathbf{K}_{\mathbf{C}}$ is the controller gain matrix (here a single line matrix with seven columns). This gain should minimize the quadratic performance index, $J$, below:

$J=\frac{1}{2} \sum_{k}\left[\mathbf{q}^{\mathbf{T}}\left(t_{k}\right) \mathbf{Q} \mathbf{q}\left(t_{k}\right)+\mathbf{c}^{\mathbf{T}}\left(t_{k}\right) \mathbf{R} \mathbf{c}\left(t_{k}\right)\right]$

The control vector is the control tension $U\left(t_{k}\right)$, a scalar. Therefore Eq. (61) can be written as:

$J=\frac{1}{2} \sum_{k}\left[\mathbf{q}^{\mathbf{T}}\left(t_{k}\right) \mathbf{Q q}\left(t_{k}\right)+\mathbf{R} U^{2}\left(t_{k}\right)\right]$

The weight matrices $\mathbf{Q}$ and $\mathbf{R}$ (this last one a scalar) should be chosen in a way where the idea of keeping $\mathrm{m}_{1}$ displacement small (to avoid crashes between the actuators surface and $\mathrm{m}_{1}$ ) is considered most crucial. Therefore, the following matrices are going to be used:

$\mathbf{Q}=\left[\begin{array}{ccccccc}100 & 0 & 0 & 0 & 0 & 0 & 0 \\ 0 & 20 & 0 & 0 & 0 & 0 & 0 \\ 0 & 0 & 1 & 0 & 0 & 0 & 0 \\ 0 & 0 & 0 & 1 & 0 & 0 & 0 \\ 0 & 0 & 0 & 0 & 1 & 0 & 0 \\ 0 & 0 & 0 & 0 & 0 & 1 & 0 \\ 0 & 0 & 0 & 0 & 0 & 0 & 1\end{array}\right]$ and $\mathbf{R}=1$

The controller gain matrix $\mathbf{K}_{\mathbf{C}}$ that minimizes $J$ is given by [20]:

$\mathbf{K}_{\mathbf{C}}=\left(\mathbf{R}+\mathbf{H}^{\mathrm{T}} \mathbf{P H}\right)^{-\mathbf{1}} \mathbf{H}^{\mathrm{T}} \mathbf{P G}$

Where $\mathbf{P}$ can be calculated from the Riccati equation, [20]:

$$
\mathbf{P}=\mathbf{Q}+\mathbf{G}^{\mathrm{T}} \mathbf{P G}-\mathbf{G}^{\mathrm{T}} \mathbf{P G}\left(\mathbf{R}+\mathbf{H}^{\mathrm{T}} \mathbf{P H}\right)^{-1} \mathbf{H}^{\mathrm{T}} \mathbf{P G}
$$

3.4 Predictive discrete linear observer design

In space-state controllers or regulators, as the LQR, all states are required for the calculation of the control signal, as shown in Eq. (60). However, as there is only one sensor in the system that measures the displacement of $\mathrm{m}_{1}$ (namely $\mathrm{u}_{5 \mathrm{G}}$ ), an observer has to be used to estimate the states. The control signal obtained with the estimated states is given by:

$$
U\left(t_{k}\right)=-\mathbf{K}_{\mathbf{C}} \hat{\mathbf{q}}\left(t_{k}\right)
$$

Besides, due to the time delay $T$, the observer will provide the states estimative in some instant $t_{k}$ with the information available at the instant $t_{k-1}$, namely the previous state estimative, $\hat{\mathbf{q}}\left(t_{k-1}\right)$, and the data obtained by the position sensor, $y\left(t_{k-1}\right)$. In this work a predictive full order observer [20] will be employed. This observer estimates the states for an instant $t_{k}$ with the following equation:

$$
\hat{\mathbf{q}}\left(t_{k}\right)=\left(\mathbf{G}-\mathbf{K}_{\mathbf{e}} \mathbf{C}-\mathbf{H} \mathbf{K}_{\mathbf{C}}\right) \hat{\mathbf{q}}\left(\mathbf{t}_{\mathbf{k}-1}\right)+\mathbf{K}_{\mathbf{e}} y\left(t_{k-1}\right)
$$

The matrix $\mathbf{C}$ relates the information provided by the sensor, $y$, with the state variables. As the sensor measures the displacement of $\mathrm{m}_{1}\left(\right.$ namely $\left.\mathrm{u}_{5 \mathrm{G}}\right)$, then: 
$\mathbf{C}=\left[\begin{array}{lllllll}1 & 0 & 0 & 0 & 0 & 0 & 0\end{array}\right]$

The matrix $\mathbf{K}_{\mathbf{e}}$ is the observer gain matrix and should be chosen in such a way to guarantee that the error dynamics is faster than the system dynamics.

The system dynamics, represented by the linear Eq. (56), can be also written as:

$\mathbf{q}\left(t_{k+1}\right)=\mathbf{G q}\left(\mathbf{t}_{\mathbf{k}}\right)+\mathbf{H c}\left(\mathbf{t}_{\mathbf{k}}\right)=\mathbf{G q}\left(\mathbf{t}_{\mathbf{k}}\right)+\mathbf{H}\left[-\left[\mathbf{K}_{\mathbf{C}}\right] \mathbf{q}\left(\mathbf{t}_{\mathbf{k}}\right)\right]=\left[\mathbf{G}-\mathbf{H} \mathbf{K}_{\mathbf{C}}\right] \mathbf{q}\left(t_{k}\right)$

The error dynamics is given by [20]:

$\mathbf{e}\left(t_{k+1}\right)=\left[\mathbf{G}-\mathbf{K}_{\mathbf{e}} \mathbf{C}\right] \mathbf{e}\left(t_{k}\right)$

Where, the error vector, $\mathbf{e}$, is the difference between the state vector and the estimated state vector:

$\mathbf{e}\left(t_{k}\right)=\mathbf{q}\left(t_{k}\right)-\hat{\mathbf{q}}\left(t_{k}\right)$

After $\mathbf{K}_{\mathbf{C}}$ is obtained, the seven poles $\left(\lambda_{s y s_{1}}, \lambda_{s y s_{2}}, \ldots, \lambda_{s y s_{7}}\right)$ of the matrix $\left[\mathbf{G}-\mathbf{H K}_{\mathbf{C}}\right]$, can be calculated with Eq. (71) and plotted at the z-plane.

$$
\left|\lambda_{\text {sys }} \mathbf{I}-\left[\mathbf{G}-\mathbf{H K}_{\mathbf{C}}\right]\right|=0
$$

As a linear quadratic regulator was used, the system dynamics should be stable. This means that all poles will be located inside the circle of radius equal to one. With the location of the poles in the z-plane, a circle touching the pole that is closer to the origin of the z-plane can be drawn. This circle has the radius $r_{\max }$.

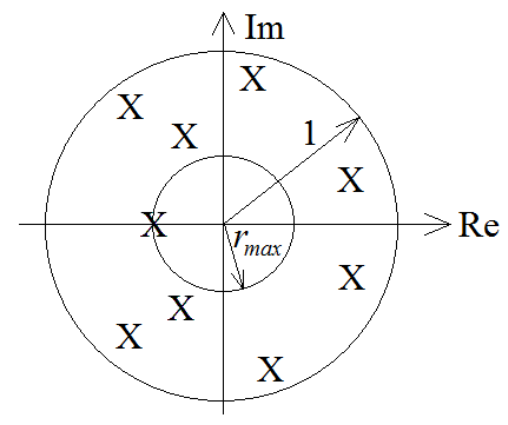

Fig. 7 Circle touching the closest linear discrete system pole to the origin of the z-plane

The values of the seven observer poles $\left(\lambda_{o b s_{1}}, \lambda_{o b s_{2}}, \ldots, \lambda_{o b s_{1}}\right)$ should be chosen inside the circle of radius $r_{\max }$. This guarantees that the discrete observer dynamics will be faster than the linear discrete system dynamics. After choosing the observer poles, the observer gain, $\mathbf{K}_{\mathrm{e}}$, can be calculated using, for example, the Ackermann Formula [20] in the matrix shown in Eq. (69), namely [G- $\left.\mathbf{K}_{\mathbf{e}} \mathbf{C}\right]$.

\section{Simulation}

\subsection{Simulation program overview}

A computer program was developed for the simulation of the structure with the actuators, a position sensor and a digital controller. In the first simulation an impulsive force is applied at $\mathrm{m}_{3}$ in a direction parallel to $\mathrm{X}$ axis, as shown in Fig. 1. The impulsive force will be modeled as a half senoid, with amplitude $F_{0}$, starting at $t_{1}$ seconds and ending at $t_{2}$ seconds. In the following simulations a harmonic force with amplitude $F_{H}$ and angular frequency $\omega$, with values until $120 \mathrm{rad} / \mathrm{s}$, will be applied.

Even though the controller and observer have been designed considering the simplified linear discrete model of the structure and actuator, the continuous non-linear model for the fifteen degrees of freedom 
structure with the two actuators, represented with Eq. (72), is used in the program. There is a set of seventeen differential equations for the non-linear model of the entire system, fifteen second order differential equations for the structure, represented with Eq. (72), one first order differential equation for the electric current at actuator $\mathrm{a}_{1}$, represented with Eq. (28), and one first order differential equation for the electric current at actuator $\mathrm{a}_{2}$, represented with Eq. (29).

$\mathbf{M}_{G} \ddot{\mathbf{u}}_{\mathbf{G}}(t)+\mathbf{D}_{G} \dot{\mathbf{u}}_{\mathbf{G}}(t)+\mathbf{K}_{G} \mathbf{u}_{\mathbf{G}}(t)=\mathbf{f}(t)$

Where:

$\mathbf{f}(t)=\left[\begin{array}{lllllllllllllll}0 & 0 & 0 & 0 & f_{a_{1}}(t)+f_{a_{2}}(t) & 0 & 0 & 0 & 0 & 0 & 0 & 0 & 0 & 0 & f(t)\end{array}\right]^{\mathbf{T}}$

$\mathbf{u}_{\mathbf{G}}(t)=\left[\begin{array}{llll}u_{1_{G}}(t) & u_{2_{G}}(t) & \ldots & u_{15_{G}}(t)\end{array}\right]^{\mathbf{T}}$

The components of the vector $\mathbf{u}_{\mathbf{G}}$ are the displacements of the structures knots, shown in Fig. 1 .

A fourth order Runge-Kutta method, [6], with constant time step of 0.0001 seconds will be employed in the simulation program. For that, it is necessary to reduce the order of Eq. (72). This can be done with the following variable substitution:

$\dot{\mathbf{u}}_{\mathbf{G}}(t)=\mathbf{v}_{\mathbf{G}}(t)$

Therefore, Eq. (72) can be written as:

$$
\mathbf{M}_{\mathbf{G}} \dot{\mathbf{v}}_{\mathbf{G}}(t)+\mathbf{C}_{\mathbf{G}} \mathbf{v}_{\mathbf{G}}(t)+\mathbf{K}_{\mathbf{G}} \mathbf{u}_{\mathbf{G}}(t)=\mathbf{f}(t)
$$

The complete set of differential equations for the non-linear model can be written with Eqs. (77)-(79), obtained from equations (28), (29) and (76).

$$
\begin{aligned}
& \dot{\mathbf{v}}_{\mathbf{G}}(t)=\mathbf{M}_{\mathbf{G}}^{-1}\left(\mathbf{f}(t)-[C]_{G} \mathbf{v}_{\mathbf{G}}(t)-[K]_{G} \mathbf{u}_{\mathbf{G}}(t)\right) \\
& \dot{i}_{a_{1}}(t)=\frac{\left[U_{0}-U(t)\right]-r i_{a_{1}}(t)+\frac{i_{a_{1}}(t) \mu_{0} N^{2} a \dot{u}_{5_{G}}(t)}{\left[s_{0}+u_{5_{G}}(t)\right]^{2}}}{L_{0}+\frac{\left(L_{\max }-L_{0}\right)}{1+\frac{\left[s_{0}+u_{5_{G}}(t)\right]}{d}\left(\frac{L_{\max }-L_{0}}{L_{d}-L_{0}}-1\right)}} \\
& \dot{i}_{a_{2}}(t)=\frac{\left[U_{0}+U(t)\right]-r i_{a_{2}}(t) \frac{i_{a_{2}}(t) \mu_{0} N^{2} a \dot{u}_{5_{G}}(t)}{\left[s_{0}-u_{5_{G}}(t)\right]^{2}}}{\left(L_{\max }-L_{0}\right)} \\
& L_{0}+\frac{\left[s_{0}-u_{5_{G}}(t)\right]^{2}}{d}\left(\frac{L_{\max }-L_{0}}{L_{d}-L_{0}}-1\right)
\end{aligned}
$$

Where the force vetor, $\mathbf{f}(t)$, is given by Eq. (73) and the actuators force are given by Eqs. (11) and (12). The control signal, $U(t)$, is updated at every $T$ seconds and remains constant until the next update (zero order hold). At some instant $k T$ the control signal, given by Eq. (65), is updated with a value calculated with the states estimative at $(k-1) \cdot T$ seconds and the information provided by the position sensor at $(k-1) \cdot T$ seconds, according to Eq. (66). The sensor output is given by Eq. (80).

$$
y\left(t_{k-1}\right)=u_{5_{G}}\left(t_{k-1}\right)+\eta\left(t_{k-1}\right)
$$


In order to avoid voltages below zero and above the saturation limit during the simulation the following routines are used in the program:

$$
\begin{aligned}
& \text { If } U_{a_{1}}>U_{\text {sup }} \text { then } U_{a_{1}}=U_{\text {sup }} \\
& \text { If } U_{a_{1}}<0 \text { then } U_{a_{1}}=0 \\
& \text { If } U_{a_{2}}>U_{\text {sup }} \text { then } U_{a_{2}}=U_{\text {sup }} \\
& \text { If } U_{a_{2}}<0 \text { then } U_{a_{2}}=0
\end{aligned}
$$

4.2 Parameters used in simulation

- $\quad$ Rigid masses: $m_{1}=0.712 \mathrm{~kg}$ and $m_{2}=m_{3}=0.428 \mathrm{~kg}$

- Flexible beams: $E=77 \mathrm{Gpa}, \rho=7860 \mathrm{~kg} / \mathrm{m}^{3}, w=0.025 \mathrm{~m}, h=0.001 \mathrm{~m}, l_{a}=0.145 \mathrm{~m}, l_{b}=0.134 \mathrm{~m}$ and $l_{c}=0.229 \mathrm{~m}$.

- Actuators: $a=0.00076 m^{2}, \quad B_{\text {lim }}=1.2 T, \quad r=59.2 \Omega, \quad N=1362, \quad \mu_{0}=4 \pi \cdot 10^{-7}, \quad s_{0}=0.003 m$, $L_{0}=0.717 \mathrm{H}, L_{\max }=1 \mathrm{H}, L_{d}=0.88 \mathrm{H}$ and $d=0.001 \mathrm{~m}$.

- Power amplifiers: $U_{\text {sup }}=24 \mathrm{~V}$

- Structure: $\zeta_{1}=\zeta_{2}=0.007, \omega_{1}=19.61 \mathrm{rad} / \mathrm{s}$ and $\omega_{2}=81.81 \mathrm{rad} / \mathrm{s}$.

- Controller: $T=0.002 \mathrm{~s}$ and $U_{0}=12 \mathrm{~V}$.

- Position sensor noise: $\eta_{\text {inf }}=-0.00001 \mathrm{~m}$ and $\eta_{\text {sup }}=0.00001 \mathrm{~m}$.

- $\quad$ Observer poles: $\lambda_{o b s_{1}}=\lambda_{o b s_{2}}=\lambda_{o b s_{3}}=\lambda_{o b s_{4}}=\lambda_{o b s_{5}}=\lambda_{o b s_{6}}=\lambda_{o b s_{7}}=0.9 r_{\max }$

- Impulsive disturbance force amplitude: $F_{0}=5 \mathrm{~N}$.

- Impulsive disturbance force starting and ending instants: $t_{1}=1 \mathrm{~s}$ and $t_{2}=1.01 \mathrm{~s}$.

- Harmonic force amplitude: $F_{H}=0.1 N$.

- Harmonic force frequencies used for the simulation of the structure with the actuators: $\omega=3,5$, $7,10,12.5,15,17.5,20,22.5,25,25.5,26,26.5,27.5,28,30,32.5,35,40,45,50,60,70,80$, $90,100,110$ and $120 \mathrm{rad} / \mathrm{s}$.

\subsection{Simulation results}

At Fig. 8 simulation results of the dynamic response when the impulsive force is applied during $0.01 s$, beginning at $t=1 \mathrm{~s}$, in the system without the electromagnetic actuators (thin line) and with the actuators (thick line) are presented. The graphs of $\mathrm{m}_{1}, \mathrm{~m}_{2}$ and $\mathrm{m}_{3}$ displacements (in meters) with respect to time (in seconds) are shown. 

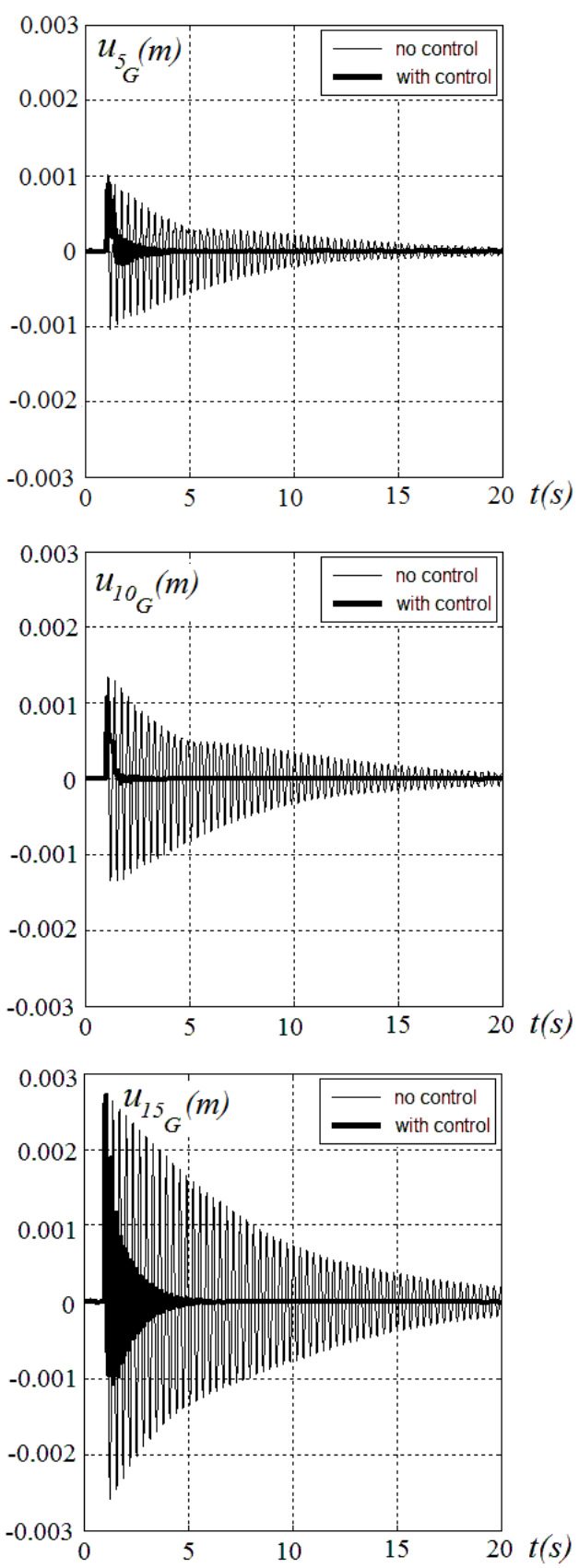

Fig. 8 Simulation results for an impulsive disturbance force

It can be seen that, even with a noisy position sensor, the displacements of all the three masses are taken back to the equilibrium position much faster when the actuators are used.

Next, results of the dynamic response when the harmonic force (with an amplitude of $0.1 \mathrm{~N}$ ) is applied are presented. At Fig. $9 \mathrm{~m}_{1}, \mathrm{~m}_{2}$ and $\mathrm{m}_{3}$ displacement amplitudes (meters in a logarithmic scale) in the steady state are shown for different harmonic disturbance force angular frequencies (rad/s in a logarithmic scale). The dots correspond to the system with the electromagnetic actuators and the continuous line correspond to the system without the actuators. 

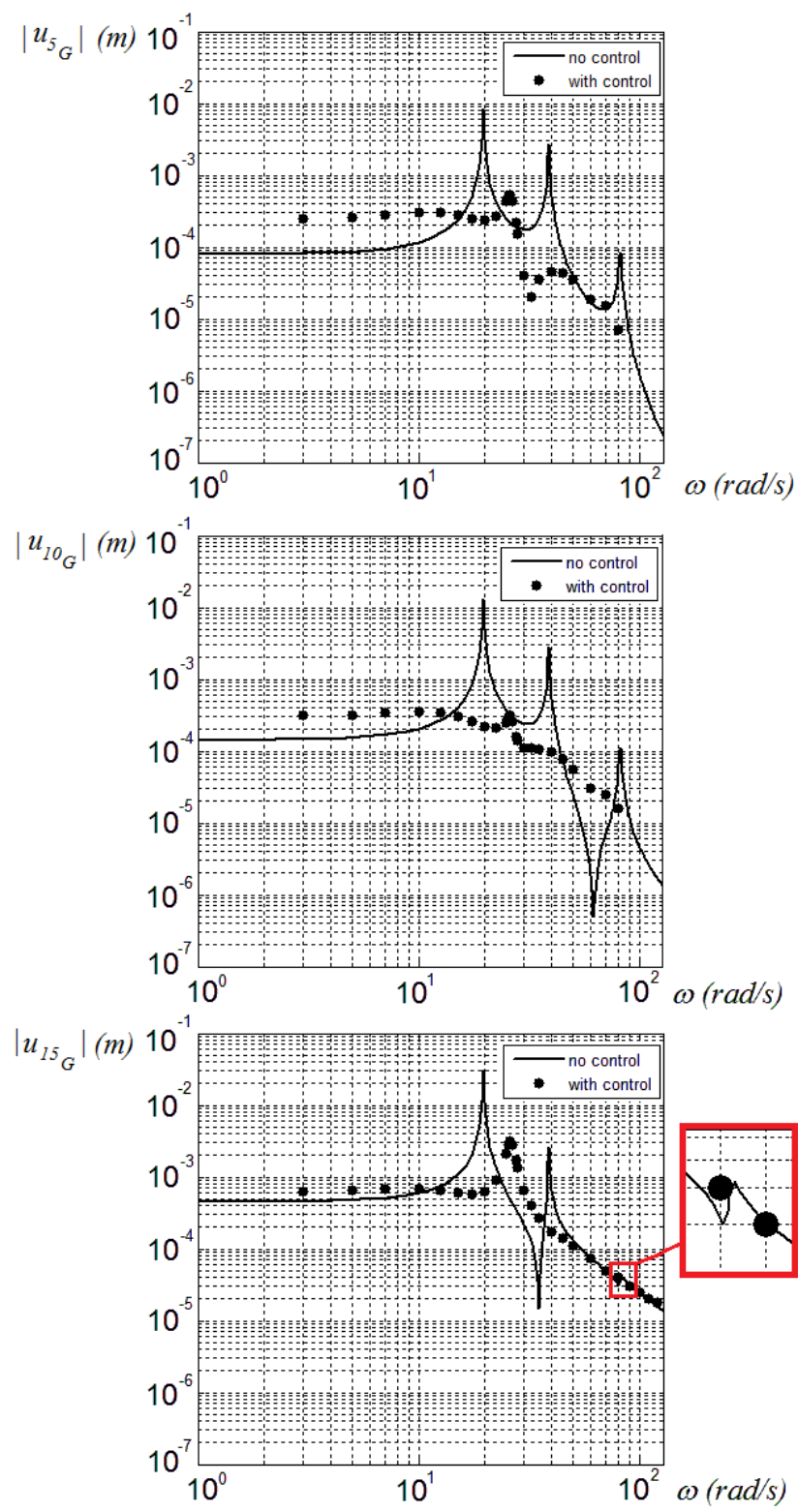

Fig. 9 Simulation results for a harmonic disturbance force

It can be seen that, even with a noisy position sensor, the oscillation amplitudes are reduced when $\omega$ is near the first natural angular frequencies of the structure.

During all the simulations, the maximum flux density was $0.073 T$, far below the saturation limit of the actuators core material, $B_{l i m}$. This means that the model for the actuators without hysteresis and saturation can be used without further concern.

\section{Conclusions}

This work presented the modeling of a flexible structure, with three rigid masses and two voltage controlled electromagnetic actuators fixed at the ground. The actuators, whose objective is to reduce the oscillations caused by external disturbances, were assembled in order to actuate at the lower mass in two collinear directions. To bring the structure back to its equilibrium position, voltages where provided to the actuators by a digital linear quadratic regulator. Since only one position sensor was assumed to be available, a full order observer was employed. For the simulation, non-linear actuator models were considered, although a linear discrete controller with a linear full order predictive discrete observer was used. Noise at the position sensor was included as well. When an impulsive force was applied at the top of the structure, the discrete controller provided adequate voltages to the electromagnetic actuators in order to bring the system back to the equilibrium position. When a harmonic force was applied the controller was able to reduce the amplitudes of oscillation when the force angular frequency was near the 
natural angular frequencies of the structure. The effectiveness of the strategy for reducing vibration with electromagnetic actuators and a space-state regulator were confirmed by the simulation results, where a comparison of the system with control and without control was shown. The results presented are encouraging, indicating that the technique employed can be effective for vibration control of structures if the electromagnetic actuators are assembled in a region where the structure oscillations are small or can be kept small by the actuators action.

\section{Appendix: Matrices elements}

Bellow, all the terms that are different to zero from the global stiffness matrix $\mathbf{K}_{\mathbf{G}}$, the global mass matrix $\mathbf{M}_{\mathbf{G}}$ (including $\mathrm{m}_{1}, \mathrm{~m}_{2}$ and $\mathrm{m}_{3}$ ) and the state matrix $\mathbf{A}$ are given.

$$
\begin{aligned}
& k_{1,1}=k_{3,3}=192 E I / l_{a}^{3} ; k_{1,5}=k_{5,1}=k_{3,5}=k_{5,3}=-96 E I / l_{a}^{3} ; k_{2,2}=k_{4,4}=16 E I / l_{a} ; \\
& k_{2,5}=k_{5,2}=k_{4,5}=k_{5,4}=24 E I / l_{a}^{2} ; k_{5,5}=\left(192 E I / l_{a}^{3}\right)+\left(192 E I / l_{b}^{3}\right) ; \\
& k_{5,6}=k_{5,8}=k_{6,5}=k_{6,10}=k_{8,5}=k_{8,10}=k_{10,6}=k_{10,8}=-96 E I / l_{b}^{3} ; \\
& k_{5,7}=k_{5,9}=k_{7,5}=k_{9,5}=-24 E I / l_{b}^{2} ; k_{6,6}=k_{8,8}=192 E I / l_{b}^{3} ; k_{7,7}=k_{9,9}=16 E I / l_{b} ; \\
& k_{7,10}=k_{10,7}=k_{9,10}=k_{10,9}=24 E I / l_{b}^{2} ; k_{10,10}=\left(192 E I / l_{b}^{3}\right)+\left(192 E I / l_{c}^{3}\right) ; \\
& k_{10,11}=k_{10,13}=k_{11,10}=k_{11,15}=k_{13,10}=k_{13,15}=k_{15,11}=k_{15,13}=-96 E I / l_{c}^{3} ; \\
& k_{10,12}=k_{10,14}=k_{12,10}=k_{14,10}=-24 E I / l_{c}^{2} ; k_{11,11}=k_{13,13}=k_{15,15}=192 E I / l_{c}^{3} ; \\
& k_{12,12}=k_{14,14}=16 E I / l_{c} ; k_{12,15}=k_{14,15}=k_{15,12}=k_{15,14}=24 E I / l_{c}^{2} . \\
& m_{1,1}=m_{3,3}=156 \rho A l_{a} / 420 ; m_{1,5}=m_{3,5}=m_{5,1}=m_{5,3}=27 \rho A l_{a} / 420 \\
& m_{2,2}=m_{4,4}=\rho A l_{a}^{3} / 420 ; m_{2,5}=m_{4,5}=m_{5,2}=m_{5,4}=-3.25 \rho A l_{a}^{3} / 420 ; \\
& m_{5,5}=\left(156 \rho A l_{a} / 420\right)+\left(156 \rho A l_{b} / 420\right)+m_{1} ; \\
& m_{5,6}=m_{5,8}=m_{6,5}=m_{6,10}=m_{8,5}=m_{8,10}=m_{10,6}=m_{10,8}=27 \rho A l_{b} / 420 ; \\
& m_{5,7}=m_{5,9}=m_{7,5}=m_{9,5}=3.25 \rho A l_{b}^{2} / 420 ; m_{6,6}=m_{8,8}=156 \rho A l_{b} / 420 ; \\
& m_{7,7}=m_{9,9}=\rho A l_{b}^{3} / 420 ; m_{7,10}=m_{9,10}=m_{10,7}=m_{10,9}=-3.25 \rho A l_{b}^{2} / 420 \\
& m_{10,10}=\left(156 \rho A l_{b} / 420\right)+\left(156 \rho A l_{c} / 420\right)+m_{2} ; \\
& m_{10,11}=m_{10,13}=m_{11,10}=m_{11,15}=m_{13,10}=m_{13,15}=m_{15,11}=m_{15,13}=27 \rho A l_{c} / 420 ; \\
& m_{10,12}=m_{10,14}=m_{12,10}=m_{14,10}=3.25 \rho A l_{c}^{2} / 420 ; m_{11,11}=m_{13,13}=156 \rho A l_{c} / 420 ; \\
& m_{12,12}=m_{14,14}=\rho A l_{c}^{3} / 420 ; m_{12,15}=m_{14,15}=m_{15,12}=m_{15,14}=-3.25 \rho A l_{c}^{3} / 420 ; \\
& m_{15,15}=\left(156 \rho A l_{c} / 420\right)+m_{3} .
\end{aligned}
$$$$
A_{1,4}=A_{2,5}=A_{3,6}=1 ; A_{4,1}=\left(k_{s}-k_{a}-k_{b}\right) / m_{1} ; A_{4,2}=k_{b} / m_{1} ;
$$$$
A_{4,4}=-\left[\alpha m_{1}+\beta\left(k_{a}+k_{b}\right)\right] / m_{1} ; A_{4,5}=\beta k_{b} / m_{1} ; A_{4,7}=k_{i} / m_{1} ; A_{5,1}=k_{b} / m_{2} ;
$$$$
A_{5,2}=\left(-k_{b}-k_{c}\right) / m_{2} ; A_{5,3}=k_{c} / m_{2} ; A_{5,4}=\beta k_{b} / m_{2} ; A_{5,5}=-\left[\alpha m_{2}+\beta\left(k_{b}+k_{c}\right)\right] / m_{2} ;
$$$$
A_{5,6}=\beta k_{c} / m_{2} ; A_{6,2}=k_{c} / m_{3} ; A_{6,3}=-k_{c} / m_{3} ; A_{6,5}=\beta k_{c} / m_{3} ;
$$$$
A_{6,6}=-\left[\alpha m_{3}+\beta k_{c}\right] / m_{3} ; A_{7,4}=-k_{u} / L_{\text {avg }} ; A_{7,7}=-r / L_{\text {avg }} \text {. }
$$

\section{References}


1. Abreu GLCM, Conceição SM, Lopes Jr V, Brennan MJ, Alves MTS (2012) System Identification and Active Vibration Control of a Flexible Structure. Journal of the Brazilian Society of Mechanical Sciences \& Engineering, Special Issue, 34:386-392

2. Abreu GLCM, Melo GP, Lopes Jr. V, Brennan MJ (2015) Active modal damping control of a smart truss structure using a self-organizing fuzzy controller. Journal of the Brazilian Society of Mechanical Sciences \& Engineering 37:441-450

3. Aly AM (2013) Vibration Control of Buildings Using Magnetorheological Damper: A New Control Algorithm. Journal of Engineering 2013:1-11

4. Boletis AR (2005) High Speed Micromotor on a Three Axis Active Magnetic Bearing. Thesis. École Polytechnique Fédérale de Lausanne

5. Bosse A, Lim TW, Shelley S (2000) Modal Filters and Neural Networks for Adaptative Vibration Control. Journal of Vibration and Control 6:631-648

6. Butcher JC (2008) Numerical Methods for Ordinary Differential Equations, 2nd ed. John Wiley \& Sons, West Sussex

7. Carvalhal R, da Silva S, Lopes Jr V (2004) Modal Control Applications in Intelligent Truss Structures. In: ABCM Symposium Series in Mechatronics Volume 1, pp 304-310

8. Carvalhal R, Lopes Jr V, Brennan MJ (2007) An efficient modal control strategy for the active vibration control of a truss structure. Shock and Vibration 14:393-406

9. Dolce M, Cardone D, Marnetto R (2000) Implementation and testing of passive control devices based on memory alloys. Earthquake Engineering and Structural Dynamics 29:945-968

10. Ebrahimpour A, Sack RL (2005) A review of vibration serviceability criteria for floor structures. Computers \& Structures 83:2488-2494

11. Fung RF, Liu YT, Wang CC (2005) Dynamic model of an electromagnetic actuator for vibration control of a cantilever beam with tip mass. Journal of Sound and Vibration 288:957-980

12. Ha QP, Nguyen MT, Li J, Kwok NM (2013) Smart Structures With Current-Driven MR Dampers: Modeling and Second-Order Sliding Mode Control. IEEE/ASME Transactions on Mechatronics 18:1702-1712

13. Hanagan LM, Murray TM, Premaratne K (2003) Controlling Floor Vibration with Active and Passive Devices. The Shock and Vibration Digest 35(5):347-365

14. Harris AF (2003) Active Vibration Absorbers for Control of Structural Vibration. Dissertation, Faculty of the Virginia Politechnic Institute and State University

15. Inman DJ (2001) Engineering Vibrations, 2nd ed. Prentice Hall, New Jersey

16. Juang JN (1984) Optimal Design of a Passive Vibration Absorber for a Truss Beam. Journal of Guidance, Control and Dynamics 7(6):733-739

17. Mahfoud J, Hagopian JD (2011) Fuzzy Active Control of Flexible Structures by Using Electromagnetic Actuators. Journal of Aerospace Engineering 24:329-337

18. Nandi A, Neogy S, Irretier H (2009) Vibration Control of a Structure and a Rotor Using One-sided Magnetic Actuator and a Digital Proportional-derivative Control. Journal of Vibration and Control 15(2):163-181

19. Occhiuzzi A, Spizzuoco M (2003) Experimental analysis of magnetorheological dampers for structural control. Smart Materials and Structures 12:703-711

20. Ogata K (1995) Discrete-Time Control Systems, 2nd ed. Prentice-Hall, New Jersey

21. Ogata K (2010) Modern Control Engineering, 5th ed. Prentice-Hall, New Jersey

22. Palomera-Arias R (2005) Passive Electromagnetic Damping Device for Motion Control of Building Structures. Thesis. Massachusetts Institute of Technology

23. Preumont A (2011) Vibration Control of Active Structures, An Introduction, 3rd ed. Springer, Berlin

24. Rao SS (2011) Mechanical Vibrations, 5th ed. Prentice Hall, New Jersey

25. Santos HFL, Trindade MA (2011) Structural Vibration Control Using Extension and Shear ActivePassive Piezoelectric Networks Including Sensitivity to Electrical Uncertainties. Journal of the Brazilian Society of Mechanical Sciences \& Engineering 33(3):287-301.

26. Schweitzer G, Bleuler H, Traxler A (1994) Active Magnetic Bearings. vdf Hochschulverlag, Zürich

27. Steffen Jr. V, Rade DA, Inman DJ (2000) Using Passive Techniques for Vibration Damping in Mechanical Systems. Journal of the Brazilian Society of Mechanical Sciences \& Engineering 22(3):411-421

28. Stephan RM, Pinto FC, Gomes ACDN, Santisteban JA, Salazar AO (2013) Mancais Magnéticos: Mecatrônica sem Atrito. Editora Ciência Moderna, Rio de Janeiro

29. Tonoli A, Amati N, Silvagni M (2010) Electromechanical Dampers for Vibration Control of Structures and Rotors. In: Vibration Control, pp 1-32 
30. Tripathi PK, Gangadharan KV (2012) Coil Based Electromagnetic Semi-Active Vibration Control for Flexible Structures. Annals of Faculty Engineering Hundeoara - International Journal of Engineering 2:185-190

31. Vianna FAC, Steffen Jr. V (2006) Multimodal vibration damping through piezoelectric patches and optimal resonant shunt circuits. Journal of the Brazilian Society of Mechanical Sciences \& Engineering 28(3):293-310

32. Wang L, Chen HH, He XD (2011) Active $\mathrm{H}_{\infty}$ control of the vibration of an axially moving cantilever beam by magnetic force. Mechanical Systems and Signal Processing 25:2863-2878

33. Wilson CMD, Abdullah MM (2010) Structural vibration reduction using self-tuning fuzzy control of magnetorheological dampers. Bulletin of Earthquake Engineering 8:1037-1054

34. Zivanovic S, Pavic A, Reynolds P (2005) Vibration serviceability of footbridges under humaninduced excitation: a literature review. Journal of Sound and Vibration 279:1-74 